\title{
Morphological and functional gastric cytoprotection by prostaglandin in rats receiving absolute ethanol orally
}

\author{
A Robert, ${ }^{\star}$ F W Leung, P H Guth
}

\begin{abstract}
Pretreatment with prostaglandins at non-antisecretory doses protects the gastric mucosa, including the parietal cells, from deep necrosis produced by intragastric administration of necrotising agents such as absolute ethanol. Whether the parietal cells also retained their ability to secrete acid when rats were pretreated with a prostaglandin, in spite of exposure to ethanol, was investigated. Gastric acid secretion was abolished 4 hours after ethanol, and secretion returned to control values only after 5-6 days. Pretreatment with a single, nonantisecretory dose of 16, 16-dimethyl prostaglandin $\mathbf{E}_{2}$ (dm $\mathbf{P G E}_{2}$ ) maintained acid secretion, in spite of exposure to absolute ethanol. Absolute ethanol caused histological changes - extensive gastric mucosal necrosis (through the muscularis mucosae), oedema, haemorrhages, polymorphonuclear infiltration, and formation of granulation tissue - that were maximal 24-48 hours after ethanol and persisted for 2 to 4 weeks. None of these changes were present in animals treated with the prostaglandin. It is concluded that a single oral pretreatment with $\mathrm{dmPGE}_{2}$ protects the gastric mucosa against not only the morphological damage of absolute ethanol (preventing necrosis, haemorrhages, and polymorphonuclear infiltration) but also the functional damage (maintaining the acid secretory function of parietal cells).
\end{abstract}

Gastric cytoprotection is the property of certain substances, particularly prostaglandins when given at non-antisecretory doses, to protect the gastric mucosa from deep necrosis after exposure to a variety of damaging agents. ${ }^{12}$ This protection has been demonstrated in animals by macroscopic inspection of the gastric mucosa, as well as by histological examination. ${ }^{3-7}$ Extensive portions of the mucosa (surface epithelium, region of the mucus neck cells, parietal cell area, and sometimes the region of chief cells) become necrotic when exposed to agents such as absolute ethanol, a strong acid, a strong base, or hypertonic solutions. Treatment beforehand with certain prostaglandins prevented necrosis of the mucosa and reduced the depth of damage in areas without gross lesions, although the surface epithelial cells still showed histological damage. ${ }^{36}$ In particular, the parietal cells looked morphologically intact. The prostaglandins also protected the gastric proliferative zone located in the mucus neck cell area, as evidenced by autoradiography after administration of $\left[{ }^{3} \mathrm{H}\right]$ thymidine.$^{6}$ The gastric mucosal lesions induced by absolute ethanol were accompanied by an impairment of gastric acid secretory function in pylorus ligated rats. A preliminary report showed that pretreatment with 16,16 -dimethyl prostaglandin $\mathrm{E}_{2}\left(\mathrm{dmPGE}_{2}\right)$ maintained gastric acid secretion after exposure to absolute ethanol. ${ }^{8}$

The aims of the present studies were to determine whether (a) the secretory impairment is due to the extensive damage to the parietal cells produced by ethanol, and (b) $\mathrm{dmPGE}_{2}$ maintains the acid secretory function of the parietal cells by preserving their morphological integrity. The time course of secretory and morphological (histological) changes induced by ethanol in control and prostaglandin-pretreated animals was also determined to establish a correlation between the structure and function of parietal cells. To this end, gastric acid secretion and histological injury were measured at various times after oral administration of absolute ethanol in rats, with and without pretreatment with $\mathrm{dmPGE}_{2}$ given at cytoprotective doses (that is non-antisecretory doses). The changes in secretion were correlated with the extent of gastric damage assessed by quantitative histology. These experiments were conducted in rats whose stomach was stimulated to secrete by either carbachol, pentagastrin, histamine, or vagal electrical stimulation.

\section{Methods}

Male and female Sprague-Dawley rats of 220 $320 \mathrm{~g}$ were fasted for 24 hours. During the last 18 hours, they were placed in individual cages to prevent coprophagy, and drinking water was removed. In the gastric secretory studies, gastric juice was collected from conscious and anaesthetised rats. In conscious animals, gastric secretion was collected after pylorus ligation and carbachol stimulation, a procedure that yields large amounts of acid. Anaesthetised rats with gastric fistulas were also used because the basal values being very low, individual secretagogues acting by different mechanisms (histamine, pentagastrin, vagal, electrical stimulation) can be studied separately. These studies were approved by the Animal Welfare Committee.

\section{STUDY IN CONSCIOUS ANIMALS}

Four groups of animals were treated orally as follows: group I: $1 \mathrm{ml}$ of the vehicle used to dissolve the prostaglandin and 30 minutes later $1 \mathrm{ml}$ of water; group II: $10 \mu \mathrm{g} / \mathrm{kg}$ of $\mathrm{dmPGE}_{2}$ (a non-antisecretory dose, see reference 11 ) in $1 \mathrm{ml}$ and 30 minutes later $1 \mathrm{ml}$ of water; group III: $1 \mathrm{ml}$ of the vehicle and 30 minutes later $1 \mathrm{ml}$ of absolute ethanol; group IV: $10 \mu \mathrm{g} / \mathrm{kg}$ of $\mathrm{dmPGE}_{2}$ 
and 30 minutes later $1 \mathrm{ml}$ of absolute ethanol. The dmPGE 2 was first diluted in a few drops of 95\% ethanol, emulphor, a vegetable oil, was added to make a final concentration of $1 \%$, and water was added to a final concentration of $5 \%$ ethanol. After these treatments, rats were divided into different groups depending on when they were studied further. No food was given to those rats that were studied at 4,8 , or 12 hours after the above treatments. Rats that were studied on day 1 were fed after the above treatments and then food was removed. Rats that were studied at 2 and 5 days after the above treatments were fed until 24 hours before the acid secretory experiments, at which time food was removed. For the acid secretory experiments, the pylorus was ligated under ether anaesthesia, and carbachol $(50 \mu \mathrm{g} / \mathrm{kg}$ in $1 \mathrm{ml}$ saline) was injected subcutaneously to stimulate acid secretion. The animals were killed 2 hours later, their gastric juice was collected and measured to the nearest $0 \cdot 1 \mathrm{ml}$. The acid content was determined by titration to pH 7 with $0.01 \mathrm{~mol} / 1 \mathrm{NaOH}$, using an automatic titrator. The results (acid concentration: $\mu \mathrm{Eq} / \mathrm{l}$; acid output: $\mu \mathrm{Eq} / 2$ hour) were expressed as a percentage of control (group I) values. The number of animals per group is shown in the Results section.

An identical experiment was performed in which the stomachs were excised for gross and histological examination at time intervals up to 10 days after giving ethanol. The animals were killed two hours after pylorus ligation, the stomachs were randomised, so that the examiner had no knowledge of the treatment given, opened along the greater curvature, rinsed in saline, and stapled to a piece of cardboard. The gross lesions were identified visually under $\times 2$ magnification and their number per stomach counted. After decoding, the average number of lesions per stomach was calculated for each group. In a separate study, this method of scoring lesions was compared with a method using a computerised image analyser, developed by Dr E H Livingston (Department of Surgery, UCLA School of Medicine, Los Angeles, CA). Absolute ethanol, $1 \mathrm{ml}$, was given orally to 82 fasted rats, and the animals were killed 2 hours later. This study consisted of the control groups of eight unrelated, consecutive experiments performed in the same laboratory and at about the same time as the present studies on functional cytoprotection. The animals in these experiments were used to validate the method of scoring the gastric lesions. The stomachs were pinned to a piece of cardboard and the lesions were counted visually. A Polaroid colour photograph $(\times 2)$ was then obtained for each stomach. The lesion area was measured by an image analyser and expressed as a percentage of the total corpus mucosal area, since the typical ethanol induced gross lesions are confined to the corpus. For each stomach, the number of lesions, assessed by visual observation, was plotted against the lesion area expressed as a percentage of total corpus mucosal area, obtained by the image analyser. A highly significant positive correlation was obtained $(r=0.86$; $p=0.0001 ; n=82$ ). Because of this close correlation, counting the number of lesions per stomach was adopted as the quantitative method to express gross gastric mucosal damage in the conscious animal studies.

After the gross lesions had been scored, the stomachs were immersed in $10 \%$ buffered formaldehyde for at least 24 hours. A section of the glandular portion was then cut with a razor blade, parallel to and approximately $0.5 \mathrm{~cm}$ from the limiting ridge that separates the glandular portion from the forestomach. The tissue was embedded in paraffin, sectioned $(6 \mu)$ and stained with haematoxylin and eosin. All slides were coded and examined blindly. The histological lesions in the gastric corpus were scored according to the rating system developed by Lacy and Ito, ${ }^{9}$ from 0 to 3: $0=$ no lesion; $1=$ damage to the surface epithelium only; 2 =damage extending down to the mucus neck cell region; $3=$ damage penetrating the parietal cell area and involving tissue necrosis. Sections of 8 to $11 \mathrm{~mm}$ in length were examined for each stomach at a magnification of $\times 100$, using an ocular micrometer equipped with a grid marked with 50 divisions. The entire length of the section was examined and scored, and the results were expressed as a percentage of the length of section for each lesion grade $(0,1,2$, and 3$)$.

In a separate study, the effect of $1 \mathrm{ml}$ of $25 \%$ ethanol given orally on acid secretion and gastric histology was examined under identical conditions (pylorus ligated 4 hours after ethanol in carbachol stimulated animals). Acid output was not affected (control, mean (SEM): 798 (31), and $25 \%$ ethanol: 696 (95) $\mu \mathrm{Eq} / 2$ hour). Histologically, the mucosa of $25 \%$ ethanol treated animals was of normal appearance, except for occasional exfoliation of surface epithelial cells. These results indicated that a much stronger concentration of ethanol is necessary to induce necrosis of parietal cells and a reduction of acid secretion. For that reason, absolute ethanol, shown earlier ${ }^{3-710}$ and in the present studies to produce extensive necrosis of parietal cells, was administered in all other studies.

\section{STUDIES IN ANAESTHETISED ANIMALS}

\section{Animal preparation}

Fasted rats were divided into three groups as follows: group 1, vehicle $(0.5 \mathrm{ml})$ used to dilute the prostaglandin followed 30 minutes later by saline ( $5 \mathrm{ml} / \mathrm{kg}$ ); group 2, vehicle followed 30 minutes later by absolute ethanol $(5 \mathrm{ml} / \mathrm{kg})$; and group 3, dmPGE $2,5 \mu \mathrm{g} / \mathrm{kg}$ (a non-antisecretory dose), followed by absolute ethanol $(5 \mathrm{ml} / \mathrm{kg})$. A dose of $5 \mu \mathrm{g} / \mathrm{kg}$ prevents deep mucosal necrosis produced by absolute ethanol. ${ }^{2}$ All agents were given intragastrically via an oral tube. The body weight of the conscious animals (first study) was quite uniform (average of $210 \mathrm{~g}$ after fasting); they received $1 \mathrm{ml}$ of $100 \%$ ethanol, which corresponds to $5 \mathrm{ml} / \mathrm{kg}$. Since the body weight of the animals of the study in anaesthetised animals was more variable, the volume was adjusted individually to $5 \mathrm{ml} / \mathrm{kg}$.

After these treatments, rats were divided into different groups depending on when they were studied further. No food was given to those rats that were studied at 4 hours after the above treatments. Rats that were studied at 1 day were 
fed after the above treatments and then food was removed. Rats that were studied at 2, 6, and 28 days after the above treatments were fed until 24 hours before the acid secretory experiments, at which time food was removed.

For the acid secretory experiments, anaesthesia was induced with urethane, $1 \mathrm{~g} / \mathrm{kg}$ intraperitoneally. Tracheostomy and laparotomy were performed. The timing of these procedures was such that the acid secretory experiments were started at 4 and 24 hours and 2, 6, and 28 days after the intragastric absolute ethanol treatment. An incision was made in the forestomach and the gastric contents were washed out with saline. A double lumen Tygon cannula was inserted through the forestomach incision and secured by a purse ligature. The pylorus was ligated and the stomach was replaced into the peritoneal cavity. The stomach was irrigated with a $0.9 \%$ saline at a rate of $0.8 \mathrm{ml} /$ minute. The gastric perfusate was collected at 15 minute intervals and titrated to $\mathrm{pH} 7$ with $0.2 \mathrm{~mol} / \mathrm{l}$ $\mathrm{NaOH}$ using an automatic titrator. The first 15 minute collection was discarded. The next two 15 minute collections were titrated and summed, and represent basal acid output in $\mu \mathrm{Eq} / 30$ minutes. Secretion was then induced with either pentagastrin $(20 \mu \mathrm{g} / \mathrm{kg} /$ hour $)$, histamine ( $3 \mathrm{mg} / \mathrm{kg} / \mathrm{hour}$ ) or vagal nerve stimulation. Pentagastrin, histamine, or saline were infused intravenously (femoral vein) at a rate of $1 \mathrm{ml} /$ hour.

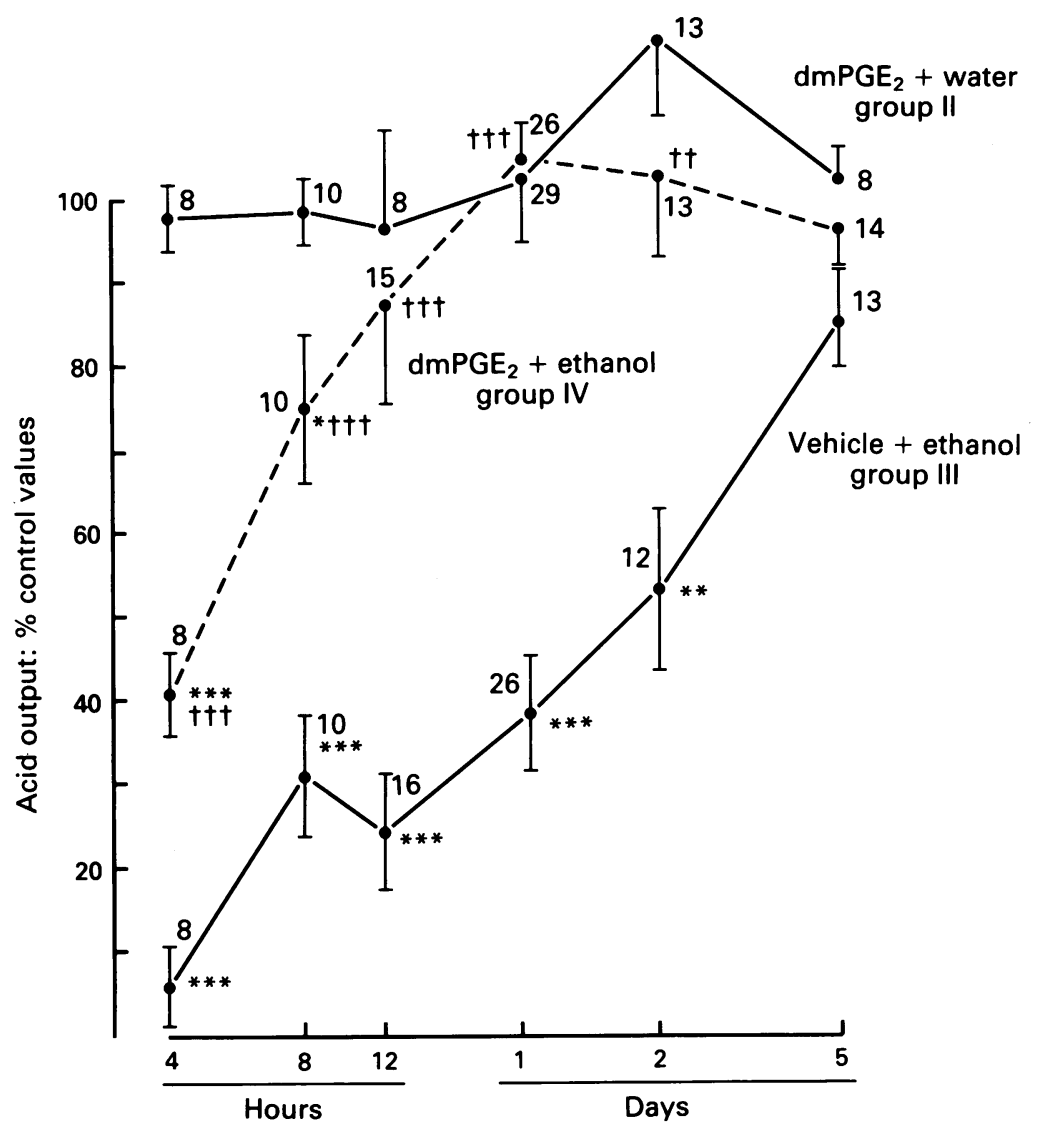

Figure 1: Effect of 16,16-dimethyl prostaglandin $E_{2}\left(d m P G E_{2}\right)$ on gastric acid concentration in animals given absolute ethanol: Time response, $d m P G E_{2}: 10 \mu \mathrm{g} / \mathrm{kg}$ orally, given 30 minutes before oral administration of $1 \mathrm{ml}$ of absolute ethanol. The pylorus was ligated under ether anaesthesia at various time intervals (4 hours to 5 days) after ethanol, and carbachol was given subcutaneously $(50 \mu \mathrm{g} / \mathrm{kg}$ ). Gastric juice was collected 2 hours after pylorus ligation. The values are expressed as percentages of the values of the control group that received vehicle and,

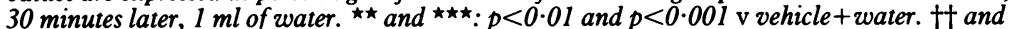
t††: $p<0.01$ and $p<0.001 \mathrm{v}$ vehicle + ethanol. Numerals: number of animals.
Stimulation and collection of gastric perfusate were continued for the following two hours.

\section{Study 1 - pentagastrin stimulation}

Pentagastrin was used to stimulate gastric acid secretion. The animals were divided into the three groups outlined above and gastric juice was collected at the following time intervals after administration of absolute ethanol: 4 and 24 hours, and 2, 6, and 28 days. At the end of the acid secretory study, the stomachs were removed and opened along the greater curvature. They were pinned out, and Polaroid photographs were taken at $\times 2$ magnification. The area with gross mucosal injury was then measured by computer image analysis, and expressed as a percentage of the total area of the corpus mucosa. A strip of stomach was cut from across the entire width of the anterior wall just below the limiting ridge for histological examination.

Studies 2 and 3 - histamine and vagal stimulation The conditions were the same as in study 1 , except that histamine (study 2 ) or vagus nerve stimulation (study 3) were used to stimulate gastric acid secretion, instead of pentagastrin. In study 3 , the subdiaphragmatic portion of the vagus nerve was isolated and transected. The distal cut end was placed between bipolar silversilver chloride electrodes and stimulated $(40 \mathrm{~V}$, $2 \mathrm{~ms}, 6 \mathrm{~Hz}$ ), as previously described. ${ }^{9}$

Study 4-effect of ethanol on gastric alkaline output A group of rats $(n=7)$ received $5 \mathrm{ml} / \mathrm{kg}$ of absolute ethanol intragastrically. They were anaesthetised with urethane and prepared for gastric irrigation for 2 hours as in study 1. The collection period was started 4 hours after the intragastric ethanol and was comparable to the two hour period in study 1 during which the animals were stimulated with secretagogues. In this study, however, saline instead of secretagogues was infused intravenously. The gastric lavage fluid was collected at 15 minute intervals. Five $\mathrm{ml}$ of the gastric fluid or a blank (saline) was mixed with $10 \mu \mathrm{Eq}$ of $\mathrm{HCl}$ and back titrated to $\mathrm{pH} 7$ with $0.1 \mathrm{~mol} / 1 \mathrm{NaOH}$. The difference between the blank titration and the gastric fluid titration corresponded to the net alkaline output in $5 \mathrm{ml}$ of fluid. The total amount of alkaline output over the two hour period was then calculated.

\section{STATISTICAL ANALYSIS}

The mean total gastric acid output during the 30 minute basal period and during the 2 hour stimulation period was computed for each study group and compared by Kruskal-Wallis one way non-parametric analysis of variance with contrasts to determine whether there were significant differences among the groups. The gross mucosal lesion scores and the percentage of the length of the deep mucosa occupied by necrosis were compared by similar analysis of variance with contrasts. For each grade of histological lesion, the percentage lengths of section in each group 


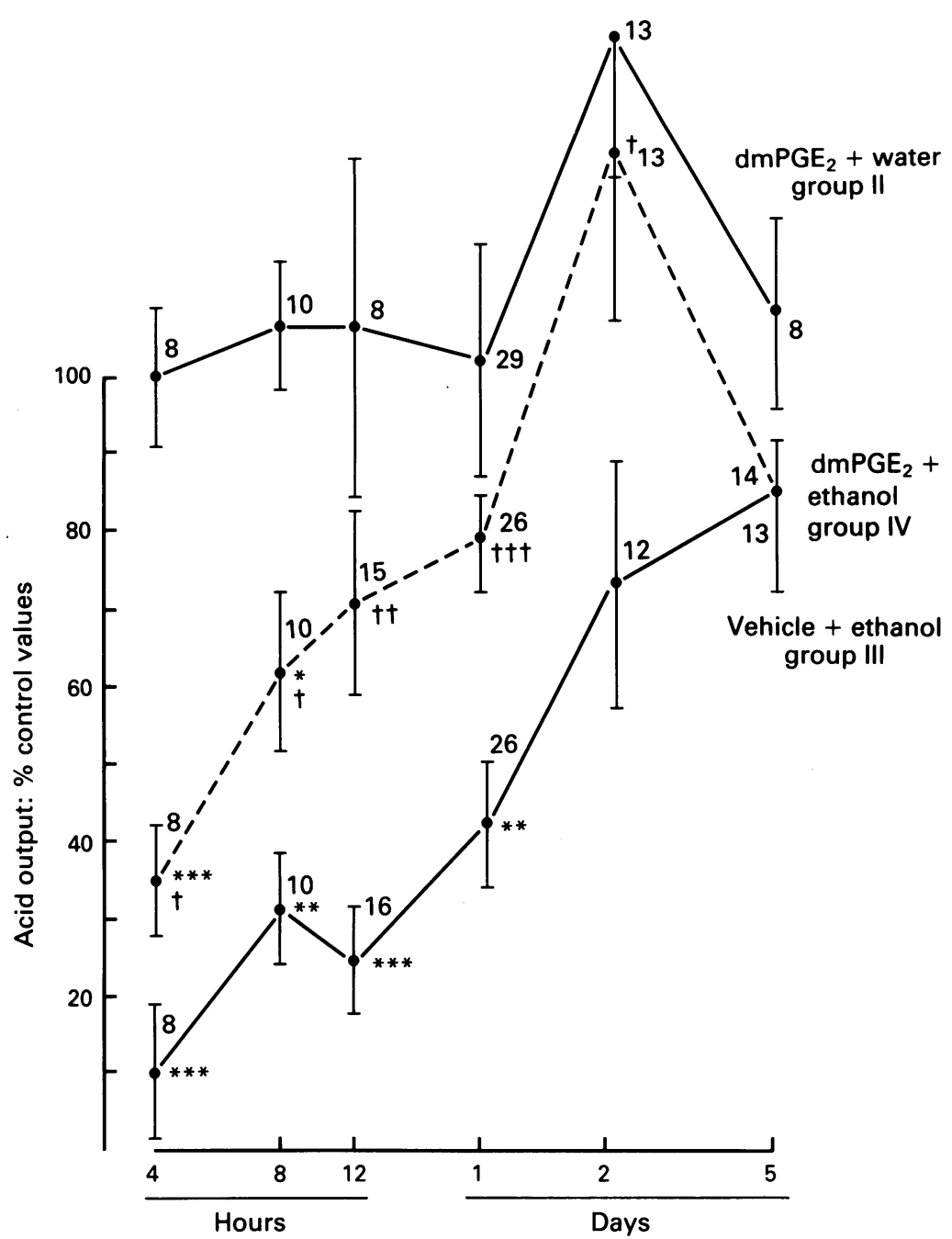

Figure 2: Effect of 16,16-dimethyl prostaglandin $E_{2}\left(d m P G E_{2}\right)$ on gastric acid output in animals given absolute ethanol: Time response. Same conditions and symbols as in Figure 1.

were compared using analysis of variance and $t$ test on rank transformation of the data. A $\mathrm{p}$ value of $<0.05$ was considered significant.

\section{Results}

\section{STUDIES IN CONSCIOUS ANIMALS}

\section{Acid secretion}

Animals receiving only the vehicle and killed 4 hours after absolute ethanol secreted almost no

TABLE I Effect of 16,16-dimethyl prostaglandin $E_{2}\left(d m P G E_{2}\right)$ on gastric juice volume in carbachol stimulated animals (values mean (SEM))

\begin{tabular}{|c|c|c|c|c|}
\hline & $\begin{array}{l}\text { Vehicle } \\
\text { +water }\end{array}$ & $\begin{array}{l}d m P G E_{2} \\
+ \text { water }\end{array}$ & $\begin{array}{l}\text { Vehicle } \\
+ \text { EtOH }\end{array}$ & $\begin{array}{l}d m P G E_{2} \\
+E T O H\end{array}$ \\
\hline \multicolumn{5}{|l|}{4 hours: } \\
\hline Volume $(\mathrm{ml} / 2 \mathrm{~h})$ & $5 \cdot 4(0 \cdot 5)$ & $5 \cdot 5(0.4)$ & $8.0(0.5)^{\star \star}$ & $4 \cdot 4(0.3)+t$ \\
\hline $\begin{array}{l}\text { Acid }(m E q / l) \\
\text { Acid output }(u E q / 2 h)\end{array}$ & $107(3)$ & $105(4)$ & $6(5)^{\star \star}$ & $44(5)^{\star \star t+f}$ \\
\hline \\
\hline Volume $(\mathrm{ml} / 2 \mathrm{~h})$ & $5.4(0.5)$ & $6.0(0.5)$ & $5 \cdot 5(0 \cdot 4)$ & $4.4(0.4) t$ \\
\hline Acid $(\mathrm{mEq} / \mathrm{l})$ & $113(5)$ & $112(5)$ & $35(8)^{\star \star}$ & $85(10)^{\star}+\dagger$ \\
\hline Acid output $(\mu \mathrm{Eq} / 2 \mathrm{~h})$ & $628(69)$ & $670(52)$ & $194(48)^{\star \star}$ & $390(65)^{\star}+$ \\
\hline \multicolumn{5}{|l|}{12 hours: } \\
\hline Volume $(\mathrm{ml} / 2 \mathrm{~h})$ & $5 \cdot 4(0 \cdot 4)$ & $6 \cdot 0(0 \cdot 7)$ & $5 \cdot 1(0 \cdot 5)$ & $4 \cdot 3(0 \cdot 3)^{\star}$ \\
\hline Acid $(\mathrm{mEq} / \mathrm{l})$ & $92(10)$ & $89(11)$ & $22(6)^{\star \star}$ & $80(10)+t$ \\
\hline Acid output $(\mu \mathrm{Eq} / 2 \mathrm{~h})$ & $513(68)$ & $546(111)$ & $125(38)^{\star \star}$ & $364(59) \dagger$ \\
\hline
\end{tabular}

$\mathrm{dmPGE}_{2}: 10 \mu \mathrm{g} / \mathrm{kg}$ given orally 30 minutes before either vehicle or absolute ethanol. Pylorus ligation and carbachol $(50 \mu \mathrm{g} / \mathrm{kg}$ subcutaneously): at various time intervals $(4,8,12$ hours) after absolute ethanol. Gastric juice collected 2 hours after pylorus ligation. EtOH $=$ ethanol. ${ }^{\star}$ and ${ }^{\star}: \mathrm{p}<0 \cdot 05$ and $\mathrm{p}<0.01 v$ vehicle + water. $\dagger$ and $\mathrm{t}+\mathrm{p}<0.05$ and $\mathrm{p}<0.01 v$ vehicle $+\mathrm{EtOH}$ acid in response to carbachol (Figure 1, acid concentration, group III, and Figure 2, acid output, group III). Table I gives the actual values for acid concentration and acid output after 4, 8, and 12 hours. With time, acid secretion slowly reappeared; however, at 2 days after ethanol, the acid concentration had returned to only $50 \%$ of the control value $(\mathrm{p}<0.01 v$ control) and acid output to only $73 \%$ of the control value $\left(\mathrm{p}<0.05 v\right.$ control). The dmPGE $\mathrm{P}_{2}$, by itself, had no effect on gastric acid secretion at this low dose of $10 \mu \mathrm{g} / \mathrm{kg}$ (group II). Animals given dmPGE 30 minutes before absolute ethanol always secreted significantly more acid than those given only absolute ethanol, regardless of when the gastric juice was collected (from 4 hours to 2 days after administration of absolute ethanol) (Figs 1 and 2, group IV). In these $\mathrm{dmPGE}_{2}$ treated animals, the decrease in acid secretion 4 hours after ethanol was not totally prevented, but was much less marked than in animals that had received ethanol alone. After 8 hours, acid secretion had returned to approximately $60 \%$ of normal values in $\mathrm{dmPGE}_{2}$ pretreated animals, whereas in vehicle treated animals acid secretion was still reduced, at approximately $30 \%$ of normal values. From the 12 th hour until the end of the experiment ( 5 days), acid concentration and output in animals that had received $\mathrm{dmPGE}_{2}$ before ethanol were not significantly different from the values of the untreated controls, not given absolute ethanol.

Table I shows the volumes of gastric juice collected 4, 8, and 12 hours after water or absolute ethanol in 2 hour pylorus ligated, carbachol treated animals. At 4 hours, absolute ethanol increased the volume by $48 \%$; this increase was totally prevented by pretreatment with dmPGE $\mathrm{d}_{2}$. At 8 and 12 hours (and later times, data not shown), ethanol no longer increased the volume of gastric juice; yet, $\mathrm{dmPGE}_{2}$ still reduced the volume by comparison with the controls.

\section{Histological changes}

Oral administration of absolute ethanol produced severe damage to the gastric mucosa, and the histological lesions evolved with time from initial necrosis to granulation tissue formation and eventually to development of new glands. Figure 3 shows that at 4 hours, less than $20 \%$ of the mucosa appeared normal histologically (grade 0 ) and the depth of necrosis was maximal (grades 1, 2 , and 3). Near complete restoration occurred only at 5 to 10 days after ethanol.

From 0 to 12 hours after ethanol, the lesions consisted of partial or total detachment of segments of the mucosa, and of large areas with necrosis and intramural haemorrhages throughout the parietal cell area (Fig $4(\mathrm{C})$ ). In much of the parietal cell region, the cell nuclei had either disappeared or were fragmented and pyknotic, and the cytoplasm had become amorphous (Fig 4(D)). Cellular membranes between cells were no longer visible, and portions of the parietal cell area appeared liquefied (Figs $4(C)$ and (D)). Marked vasodilatation and congestion of mucosal vessels were apparent, particularly in the luminal third of the mucosa. 
Grade 0
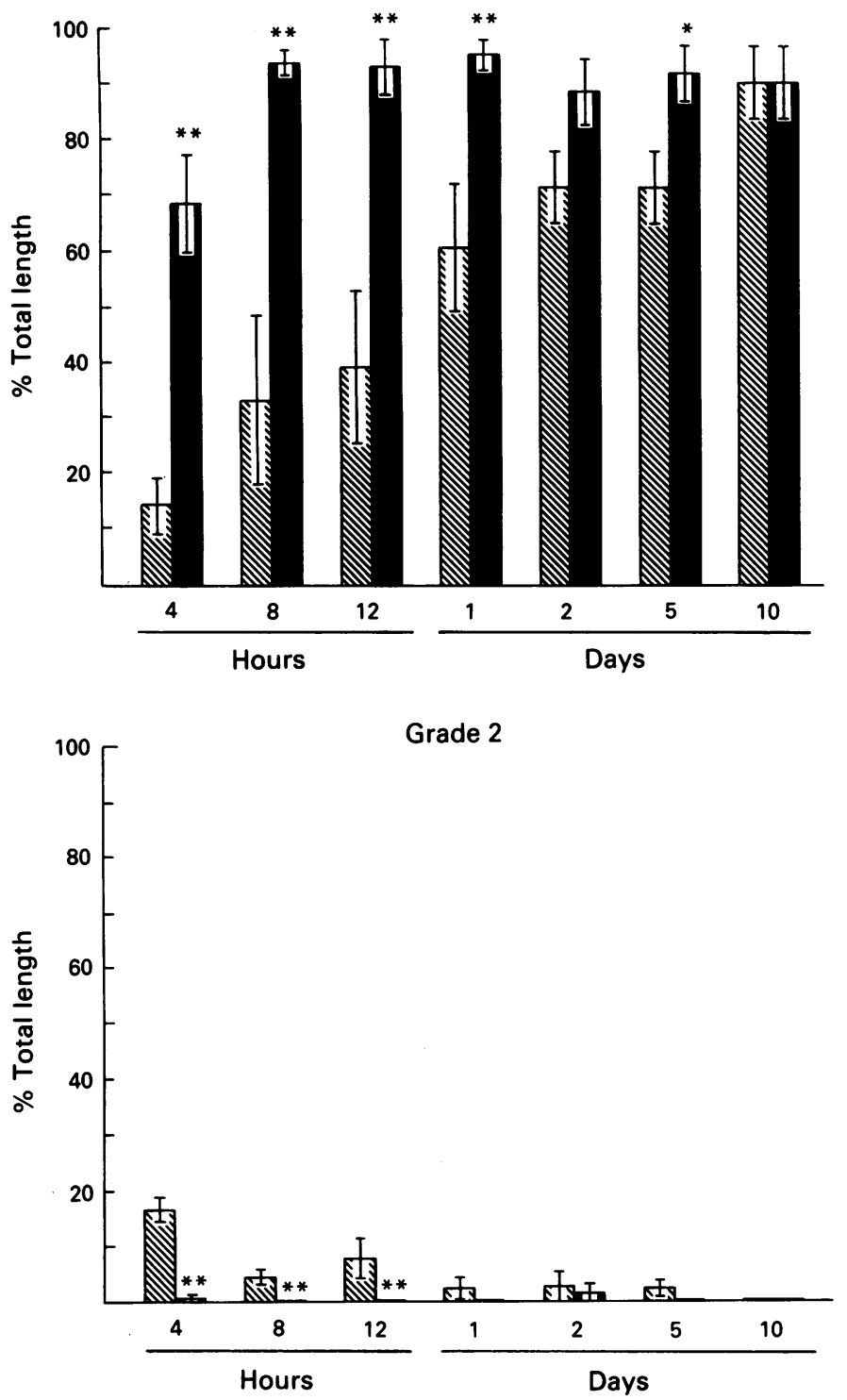

Grade 1

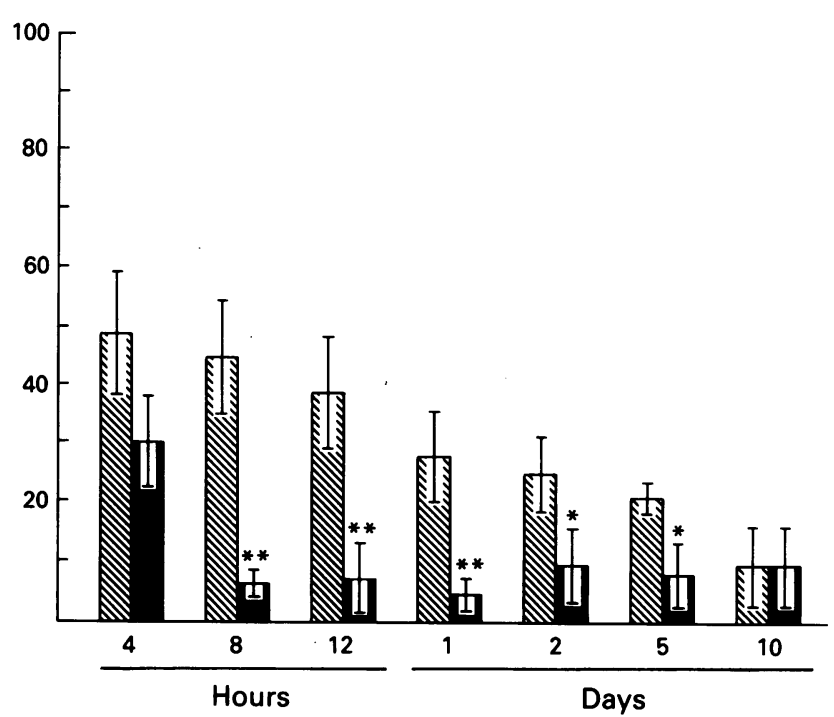

Grade 3

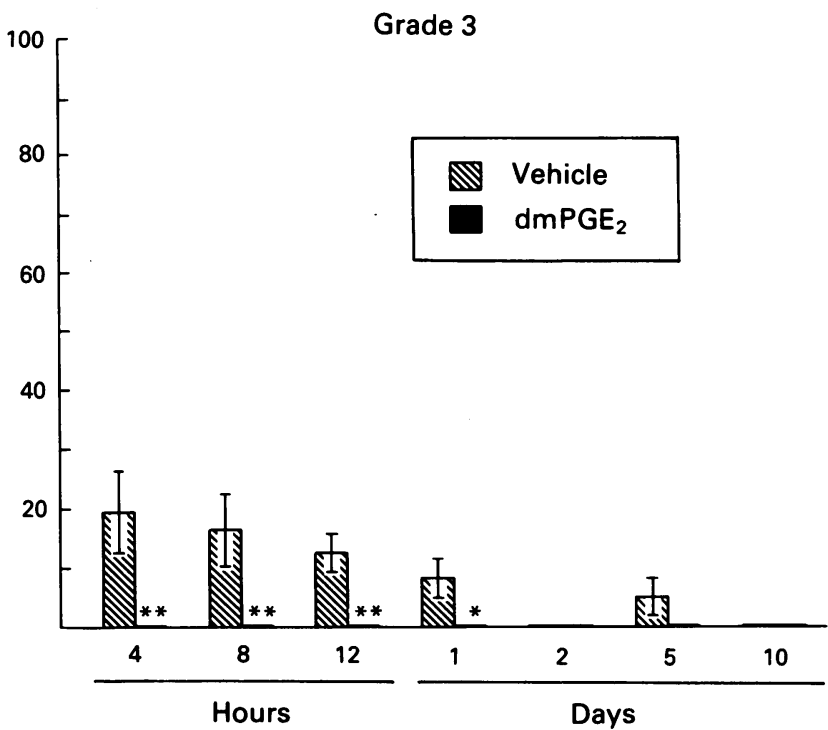

Figure 3: Effect of 16,16-dimethyl prostaglandin $E_{2}\left(d m P G E_{2}\right)$ on histological changes after absolute ethanol: Time response. Same conditions as in Figures 1 and 2. Grades 0, 1, 2, and 3: see definitions in Methods section. ${ }^{\star}$ and ${ }^{\star}$ : $p<0.05$ and $p<0.01 \mathrm{v}$ corresponding vehicle group. $n=6$.

From 12 to 48 hours after ethanol, coagulation necrosis had developed in the parietal cell area, accompanied with heavy polymorphonuclear (PMN) infiltration. Thick bands of PMNs were present within the necrotic masses (Figs $4(\mathrm{E})$ and (F)). The submucosa was oedematous and also infiltrated with PMNs (Fig 4(E)).

From 2 to 6 days after ethanol, the necrotic tissue gradually sloughed off, the mucosa and submucosa were replaced by granulation tissue, and the muscularis mucosae was interrupted (Fig 4 (I)). A single layer of surface epithelium originating from the edges of the defect progressed towards the granulation tissue, and eventually covered it entirely (Fig 4(I)).

From 6 to 28 days after ethanol, the mucosa regenerated. The granulation tissue disappeared and glands reformed.

By day 28 , most of the mucosa had regained normal appearance, although in several areas the corpus mucosa was immature, being devoid of parietal and chief cells and consisting solely of mucus cells, thus resembling the antral mucosa (Figs $4(\mathrm{~J})$ and $(\mathrm{K})$ ). Many glands had a cystic appearance (Fig 4(J)).
In contrast to the above mentioned changes, in animals pretreated with a single oral, non-antisecretory dose of $\mathrm{dmPGE}_{2}(5$ or $10 \mu \mathrm{g} / \mathrm{kg}),{ }^{11}$ and then given absolute ethanol, the histological damage was minimal and limited to the surface epithelium. Figure 3 shows that $\mathrm{dmPGE}_{2}$ completely prevented the deep necrotic lesions (grades 2 and 3 ) produced by absolute ethanol, and significantly reduced the surface epithelial damage (grade 1) at all time intervals. Gastric glands and parietal cells looked structurally normal as in control animals not given ethanol (Figs $4(\mathrm{G})$ and $(\mathrm{H})$ ). When viewed at high magnification $(\times 250)$, their nuclei had normal appearance, with visible nucleolus and chromatin grains, and the cytoplasm contained distinct organelles. Pretreatment with $\mathrm{dmPGE}_{2}$ prevented the necrosis and the PMN infiltration, although spotty exfoliation of surface epithelial cells persisted (Fig 4(G)). However, except at the 4 hour interval after ethanol, the degree of damage to the surface epithelium in the prostaglandin pretreated animals was always significantly less than that in control animals that had received only ethanol (Fig 3 , grade 1 ). 

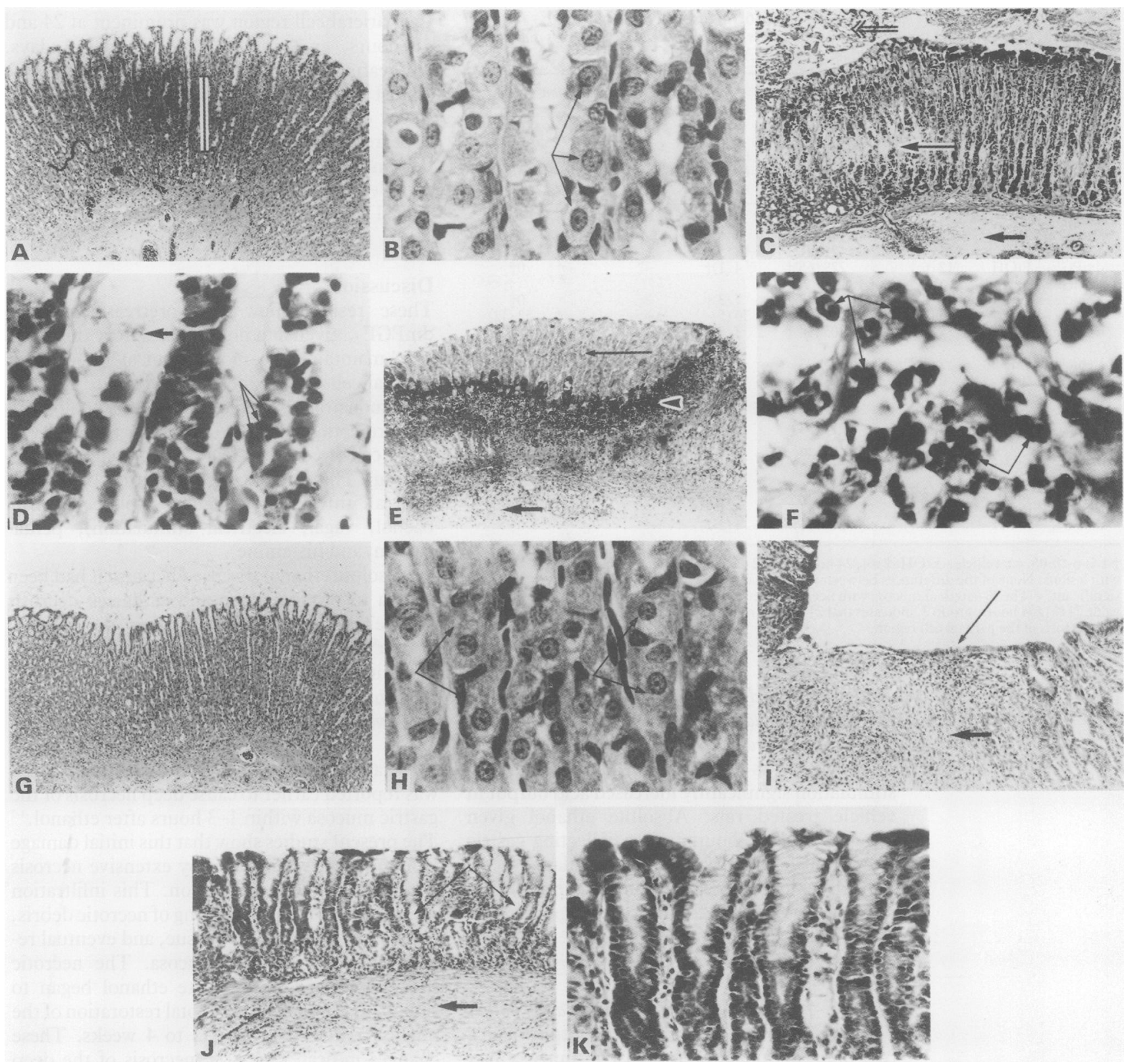

Figure 4: Time course of gastric (corpus) histological changes produced by absolute ethanol, with and without 16,16-dimethyl prostaglandin $E_{2}\left(d m P G E_{2}\right)$ pretreatment, in conscious rats. Haematoxylin and eosin stain. (A) Control mucosa. Parietal cell region is indicated with bracket. (Original magnification $\times 25$.) (B) Parietal cell region, from Figure 4(A). Normal parietal cells (arrows). (Original magnification $\times 250$.) (C) Absolute ethanol, killed after 4 hours. Most of the mucosa is necrotic. There is apparent liquefaction of areas of the parietal cell region (middle arrow), cell debris in gastric lumen (top arrow), and submucosal oedema (bottom arrow). (Original magnification $\times 25$.) (D) Magnified view (original magnification $\times 250$ ) of the parietal cell region from Figure $4(C)$. Strands of gland remnants consisting mostly of parietal cells with pyknotic nuclei are seen (thin arrows). These strands are separated by liquefied tissue (thick arrow).

(E) Absolute ethanol, killed after 48 hours. There is coagulation necrosis of most of the mucosa, including the parietal cell region (thin arrow). A thick layer of polymorphonuclear cells (arrow head) separates dead from living tissue. The muscularis mucosa is also damaged. Oedema and infiltration with inflammatory cells of the submucosa is seen (thick arrows). (Original magnification $\times 25$.) $(F)$ Polymorphonuclear cell layer, from Figure 4(E). Parietal cells have disappeared and are replaced by polymorphonuclear cells (arrows). (Original magnification $\times 500$.) $(G)$ Absolute ethanol and pretreatment with dmPGE, $10 \mu g / k g, k i l l e d ~ 4$ hours after ethanol. The mucosa is intact (no necrosis, no haemorrhage, no polymorphonuclear infiltration). Some exfoliation of the surface epithelium persists. $($ Original magnification $\times 25$.) $(H)$ Magnified view (original magnification $\times 250$ ) of the parietal cell region, from Figure $4(G)$. The parietal cells have normal appearance and the gland structure is intact (arrows). (I) Gastric mucosa (corpus), six days after absolute ethanol. (Original magnification $\times 40$.) The necrotic tissue has been sloughed off and has been replaced by thick granulation tissue (thick arrow), infiltrated with inflammatory cells. The muscularis mucosa is absent. A monolayer of flattened, columnar epithelial cells (thin arrow) originating from the edges of the defect covers the granulation tissue. Invaginations from the monolayer near the ulcer margin represents beginning reformation of glands. Outside the granulation tissue are normally appearing gastric glands. (f) Gastric mucosa (corpus), 28 days after absolute ethanol. (Original magnification $\times 40$.) Regeneration of immature glands, consisting of mucus cells resembling antral mucosa, can be seen. Multiple cyst formation (thin arrows), probably representing dilatation of these immature glands, is present. The submucosa consists of granulation tissue with connective tissue fibres, capillaries and inflammatory cells (thick arrow). (K) Gastric mucosa (corpus), 28 days after ethanol. (Original magnification $\times 100$.) Regenerated antral like glands are composed exclusively of mucus cells, and no parietal or chief cells are visible.

\section{STUDIES IN ANAESTHETISED ANIMALS}

Study 1 - time course of ethanol induced changes in pentagastrin stimulated animals

Table II shows the basal and stimulated gastric acid output obtained at 4, 24, 48 hours, and 6 and 28 days after intragastric absolute ethanol or vehicle. Pentagastrin significantly increased acid output in control rats. Absolute ethanol abolished basal and pentagastrin stimulated secretion in vehicle pretreated rats at 4 and 24 hours. Partial recovery occurred at 2 and 6 days, and complete recovery was evident at 28 days. In rats given $\mathrm{dmPGE}_{2}$ the secretory response was preserved at all times. 
TABLE II Effect of absolute ethanol $(E t O H)$ and 16,16 dimethyl prostaglandin $E_{2}$ (dmPGE $E_{2}$ on acid output stimulated by pentagastrin, and on gastric lesions (gross and histological), in anaesthetised rats (values mean $(S E M))$

\begin{tabular}{|c|c|c|c|c|c|}
\hline & \multirow{2}{*}{\multicolumn{2}{|c|}{ Gastric acid output $(\mu E q)$}} & \multirow{3}{*}{$\begin{array}{l}\text { Gross } \\
\text { lesion } \\
\text { scores }^{\star}\end{array}$} & \multicolumn{2}{|c|}{ Histological lesions } \\
\hline & & & & \multirow{2}{*}{$\begin{array}{l}\text { Coagulation } \\
\text { necrosis with } \\
\text { inflammatory } \\
\text { cell } \\
\text { infiltration }\end{array}$} & \multirow{2}{*}{$\begin{array}{l}\% \text { Length } \\
\text { of mucosa } \\
\text { with } \\
\text { necrosis\# }\end{array}$} \\
\hline & $\begin{array}{l}30 \text { Minute } \\
\text { basal }\end{array}$ & $\begin{array}{l}2 \text { Hour } \\
\text { stimulated }\end{array}$ & & & \\
\hline \multicolumn{6}{|l|}{4 Hours: } \\
\hline $\begin{array}{l}\text { Vehicle+ saline } \\
\text { Vehicle+EtOH } \\
\text { dmPGE }_{2}+\mathrm{EtOH}^{2}\end{array}$ & $\begin{array}{l}28(13) \dagger \\
1(1) \\
12(6) \dagger\end{array}$ & $\begin{array}{l}199(43) \dagger \\
21(11) \\
229(65) \dagger\end{array}$ & $\begin{array}{c}1(6) \dagger \\
18(5) \\
4(1) \dagger\end{array}$ & $\begin{array}{l}- \\
\overline{-}\end{array}$ & $\begin{array}{l}0 \dagger \\
21(6) \\
0 \dagger\end{array}$ \\
\hline 24 Hours: & $15(8)+$ & $179(33) t$ & $7(3) t$ & - & $0 \dagger$ \\
\hline $\begin{array}{l}\text { Vehicle+salıne } \\
\text { Vehicle+EtOH } \\
\text { dmPGE }_{2}+\mathrm{EtOH}\end{array}$ & $\begin{array}{l}15(8) \dagger \\
3(1) \\
7(1 \cdot 5) \dagger\end{array}$ & $\begin{array}{l}179(33) \dagger \\
17(5) \\
205(34) \dagger\end{array}$ & $\begin{array}{c}7(3) \dagger \\
36(5) \\
3(2) \dagger\end{array}$ & $\overline{+}$ & $\begin{array}{c}0 \dagger \\
52(12) \\
0 \dagger\end{array}$ \\
\hline \multicolumn{6}{|l|}{2 Days: } \\
\hline Vehicle+saline & $7(3 \cdot 2) \dagger$ & $175(23)$ & $3(1) t$ & & \\
\hline Vehicle+EtOH & $0.4(0.1)$ & $103(41)$ & $44(12)$ & + & $27(9)$ \\
\hline $\mathrm{dmPGE}_{2}+\mathrm{EtOH}$ & $7(2 \cdot 9) \dagger$ & $184(29)$ & $7(4) \dagger$ & - & $0 \dagger$ \\
\hline \multicolumn{6}{|l|}{6 Days: } \\
\hline Vehicle+EtOH & $2(0.6)$ & $124(27)$ & $3(0.6)$ & + & $11(4) \varsigma$ \\
\hline $\mathrm{dmPGE}_{2}+\mathrm{EtOH}$ & $2(0 \cdot 6)$ & $154(27)$ & $4(1 \cdot 6)$ & - & $0+$ \\
\hline \multicolumn{6}{|l|}{28 Days: } \\
\hline Vehicle+saline & $8(2 \cdot 7)$ & $253(47)$ & $1(0 \cdot 5)$ & - & $0 f^{2}$ \\
\hline $\begin{array}{l}\text { Vehicle+EtOH } \\
\text { dmPGE }_{2}+\text { EtOH }\end{array}$ & $\begin{array}{r}7(1 \cdot 7) \\
10(2 \cdot 4)\end{array}$ & $\begin{array}{l}274(37) \\
240(16)\end{array}$ & $\begin{array}{l}6(1 \cdot 9) \\
4(2 \cdot 2)\end{array}$ & $\begin{array}{l}- \\
-\end{array}$ & $\begin{array}{l}3(2) \mp \\
0+\end{array}$ \\
\hline
\end{tabular}

$\dagger \neq \S: \mathrm{p}<0 \cdot 05 . \dagger v$ vehicle $+\mathrm{EtOH} ; \ddagger v 4,24$ hours, and 2 days; $₫ v 24$ hours. ${ }^{\star}$ Expressed as $\%$ mucos with lesions. None of the differences between vehicle + saline and dmPGE $2+\mathrm{EtOH}$ were statistically significant. \# The \% length of mucosa with necrosis refers to deep necrosis (grade 3 ). Thus the value 21 (6) at 4 hours, group 2 , indicates that 21 (6)\% of mucosa of the histological slides in that group had necrosis of the parietal cell region.
Study 2 and Study 3 - effect of intragastric $d m P G E_{2}$ on histamine and vagal stimulated acid secretion in animals receiving absolute ethanol Table III shows that histamine and vagus nerve stimulation significantly increased acid output in vehicle treated rats. Absolute ethanol given intragastrically 4 hours before collecting gastric juice abolished both basal and stimulated secretion in vehicle pretreated rats. In the dmPGE pretreated rats, the secretory response was preserved.

Study 4-effect of ethanol on gastric alkaline output The total amount of net alkaline output over a two hour period after the gastric mucosa had been injured with absolute ethanol was 23 (6) $\mu \mathrm{Eq}$. As shown in Table II, the two hour stimulated gastric acid output in control rats ranged from 175 to $253 \mu \mathrm{Eq}$. At 4 and 24 hours after gastric mucosal injury by absolute ethanol, the net titratable acid under similar stimulatory condition was reduced to approximately $10 \%$ of the values obtained in control animals.

\section{MORPHOLOGICAL CHANGES}

Gross lesions

The gross lesion scores in studies 1,2 , and 3 are shown in Tables II and III. Pretreatment with $\mathrm{dmPGE}_{2}$ markedly and significantly reduced the formation of gross lesions by absolute ethanol.

\section{Histological changes}

Table II shows the time course of histological changes observed in study 1 . In the vehicle pretreated rats given intragastric absolute ethanol, necrotic mucosal changes were present in the parietal cell area between 4 and 48 hours. Extensive necrosis with PMN infiltration within the parietal cell region was prominent at 24 and 48 hours, and was still visible after 6 days. Thereafter, these changes diminished and were almost completely resolved at 1 month. Even then, certain regions of the corpus mucosa appeared immature, with short glands resembling antral mucosa. Pretreatment with $\mathrm{dmPGE}_{2}$ completely prevented formation of these histological lesions.

\section{Discussion}

These results show that pretreatment with $\mathrm{dmPGE}_{2}$, given at a non-antisecretory dose, not only maintains the morphological integrity of parietal cells after exposure to absolute ethanol, as demonstrated histologically ('morphological' cytoprotection), but also maintains the ability of these cells to secrete acid ('functional' cytoprotection). This was demonstrated after stimulation with all three secretagogues (cholinergic (carbachol, vagal, electrical stimulation), pentagastrin, and histamine).

Absolute ethanol was used because it had been shown to produce deep and extensive necrosis of the gastric mucosa affecting the parietal region $^{3-7}{ }^{10}$; damage to these cells was a prerequisite for our studies. Necrosis of parietal cells in animals receiving absolute ethanol only was evidenced by the abundance of pyknotic nuclei and disappearance of cell membranes. Intragastric administration of absolute ethanol was reported earlier to cause deep necrosis of the gastric mucosa within 1-3 hours after ethanol. ${ }^{3-7}$ The present studies show that this initial damage is followed after 24 hours by extensive necrosis and massive PMN infiltration. This infiltration eventually leads to the clearing of necrotic debris, formation of granulation tissue, and eventual reepithelialisation of the mucosa. The necrotic tissue produced by absolute ethanol began to slough off after 2 days, but total restoration of the mucosa required at least 2 to 4 weeks. These changes indicate that true necrosis of the deep mucosa had taken place after contact with absolute ethanol. The extent of the damage (penetrating the muscularis mucosa) and the type of healing (monolayer of epithelial cells covering the mucosa, and new gland formation) indicate that the lesions represent ulcers, not just erosions. By contrast, no such leukocytic infiltration or lesion formation occurred in animals pretreated with $\mathrm{dmPGE}_{2}$, indicating that deep gastric mucosal necrosis, seen in the controls receiving only ethanol, did not develop in these animals. The decrease in acid secretion observed in the present studies was associated with mucosal necrosis during the first 24 hours after ethanol administration. The low acid values observed during the first two days after ethanol may also be ascribed to diffusion of alkaline interstitial fluid consequent upon the epithelial damage caused by ethanol. This was followed by gradual resumption of acid secretion and by progressive healing of the mucosa over the course of the next 4-6 days.

In conscious animals, carbachol induced acid secretion was abolished 4 hours after ethanol. It was much less reduced in animals pretreated with $\mathrm{dmPGE}_{2}$, the acid secretory response to 
TABLE III Effect of absolute ethanol $(E t O H)$ and 16,16-dimethyl prostaglandin $E_{2}$ ( $\mathrm{dmPGE}_{2}$ ) on acid output induced by either histamine or vagus nerve stimulation, and on gastric lesions (gross and histological), in anaesthetised rats (values mean (SEM))

\begin{tabular}{|c|c|c|c|c|}
\hline & \multicolumn{2}{|c|}{ Gastric acid output $(\mu E q)$} & \multirow[b]{2}{*}{$\begin{array}{l}\text { Gross lesion } \\
\text { scorest }\end{array}$} & \multirow{2}{*}{$\begin{array}{l}\text { Histological } \\
\text { lesions } \\
\% \text { length of } \\
\text { mucosa with } \\
\text { necrosis } \ddagger\end{array}$} \\
\hline & $\begin{array}{l}30 \text { Minute } \\
\text { basal }\end{array}$ & $\begin{array}{l}2 \text { Hour } \\
\text { stimulated }\end{array}$ & & \\
\hline \multicolumn{5}{|l|}{ Histamine: } \\
\hline Vehicle+saline & $2(1)$ & $82(16)^{\star}$ & $3(1 \cdot 7)^{\star}$ & $0^{\star}$ \\
\hline Vehicle+EtOH & $0(0)$ & $1.8(1)$ & $51(8)$ & $52(12)$ \\
\hline $\mathrm{dmPGE}_{2}+\mathrm{EtOH}$ & $7(5 \cdot 5)^{\star}$ & $40(12)^{\star}$ & $2(1)^{\star}$ & $0^{\star}$ \\
\hline \multicolumn{5}{|l|}{ Vagus nerve stimulation: } \\
\hline Vehicle + saline & $4(1 \cdot 1)^{\star}$ & $296(67)^{\star}$ & $6(2)^{\star}$ & $0^{\star}$ \\
\hline Vehicle +EtOH & $0 \cdot 3(0 \cdot 1)$ & $29(24)$ & $25(5)$ & $17(8)$ \\
\hline $\mathrm{dmPGE}_{2}+\mathrm{EtOH}$ & $1(0 \cdot 6)$ & $209(49)^{\star}$ & $4(1 \cdot 4)^{\star}$ & $0^{\star}$ \\
\hline
\end{tabular}

Animals were killed 4 hours after $100 \%$ ethanol.

$\star v$ Vehicle $+\mathrm{EtOH} ; \mathrm{p}<0.05$. Expressed as \% mucosa with lesions. The differences between vehicle+saline and dmPGE $2+$ EtOH were not statistically significant. ‡same as \# Table II.

carbachol being still 7 times (concentration) and 3.5 times (output) higher in $\mathrm{dmPGE}_{2}$ pretreated than in vehicle pretreated animals (Figs 1 and 2). This shows that in $\mathrm{dmPGE}_{2}$ treated conscious animals, the intragastric administration of ethanol produced only a partial and transient parietal cell dysfunction. The fact that secretion returned to near normal in 8 hours suggests that this initial cellular 'shock' was reversible in $\mathrm{dmPGE}_{2}$ treated animals and had not damaged the intracellular structures responsible for acid secretion. The increase in gastric juice volume four hours after absolute ethanol (Table I) probably reflects the passage of plasma into the lumen as a result of the extensive damage of the mucosa.

The result of study 4 shows that over a comparable 2 hour period the net alkaline output produced by the ethanol injured mucosa was only $23 \mu \mathrm{Eq}$. This observation suggests that the alkaline secretion, albeit present, was not sufficient to account for the large drop in titratable acid after application of absolute ethanol.

Functional cytoprotection by $\mathrm{dmPGE}_{2}$ occurred sooner in anaesthetised than in conscious rats. In anaesthetised animals given ethanol and pretreated with $\mathrm{dmPGE}_{2}$, the acid response at 4 hours was almost identical to that of controls receiving only saline, regardless of the stimulus (pentagastrin, histamine, or vagal stimulation). Such rapid functional recovery cannot be explained by cell replication. It is more likely that in animals given $\mathrm{dmPGE}_{2}$ beforehand the parietal cells did not become necrotic after exposure to absolute ethanol; their function that is, acid secretion - was temporarily diminished, but was quickly restored.

The presence of damage to the surface epithelium during the first 4 hours after absolute ethanol in animals given dmPGE ${ }_{2}$ confirms previous reports showing that $\mathrm{dmPGE}_{2}$ does not protect that portion of the mucosa. ${ }^{36}{ }^{10}$ In animals receiving only absolute ethanol, the damage to the surface epithelium decreased very slowly with time, requiring approximately 10 days to disappear. It is noteworthy that in animals given
$\mathrm{dmPGE}_{2} 30$ minutes before absolute ethanol, the rate and extent of repair were much faster (as depicted in Figure 3, grade 1 lesion) than in untreated animals. The prostaglandin appears to accelerate the repair process, presumably by enhancing epithelial restitution of the surface epithelium. Schmidt, et al, ${ }^{510}$ also reported that $\mathrm{dmPGE}_{2}$ accelerated the repair of the gastric surface epithelium after damage by absolute ethanol.

In conclusion, the present studies show that oral administration of absolute ethanol abolishes gastric acid secretion largely because of the massive necrosis of the parietal cell region. This necrosis is evidenced by the histological changes seen in parietal cells. However, the inhibition of acid secretion is also due to functional impairment of parietal cells, not detectable by light microscopy, since anacidity was nearly total after administration of ethanol whereas necrosis (gross and histological) was of the order of $18-50 \%$. Pretreatment with dmPGE ${ }_{2}$, given orally at nonantisecretory doses before administration of the necrotising agent (absolute ethanol), not only protects parietal cells from necrosis, as evidenced by histological examination ('morphological' cytoprotection), but also maintains the ability of the parietal cells to secrete acid ('functional' cytoprotection).

The authors thank Cleo Lancaster, Adalsteinn S Olafsson, Susan $\mathrm{K}$ Gilbertson-Beadling, and Gary Paulsen for their expert technical assistance, and Edward $\mathrm{H}$ Livingston, M.D., for assistance in image analysis of the lesions. This work was supported in part by Veterans Administration Medical Research Funds.

1 Robert A. Cytoprotection by prostaglandins. Gastroenterology 1979; 77: 761-7.

2 Robert A, Nezamis JE, Lancaster C, Hanchar AJ. Cytoprotection by prostaglandins in rats. Prevention of gastric protection by prostaglandins in rats. Prevention of gastric $\mathrm{NaCl}$, and thermal injury. Gastroenterology 1979; 77: $\mathrm{NaCl}$, and

3 Guth PH, Paulsen G, Nagata H. Histologic and microcirculatory changes in alcohol-induced gastric lesions in the rat: effect of prostaglandin cytoprotection. Gastroenterology 1984; 87: 1083-90.

4 Lacy ER, Ito $S$. Microscopic analysis of ethanol damage to rat gastric mucosa after treatment with a prostaglandin. Gastroenterology 1982; 83: 619-25.

5 Schmidt KL, Henagan JM, Hilburn PJ, Miller TA. Prostaglandin cytoprotection against ethanol-induced gastric injury in the rat: a histologic and cytologic study of the injury in the rat: a histologic and cytologic study
surface epithelium. Gastroenterology 1985; 88: 649-59.

6 Tarnawski A, Hollander D, Stachura J, Krause WJ, Gergely $H$. Prostaglandin protection of the gastric mucosa against alcohol injury - a dynamic time-related process. Role of the mucosal proliferative zone. Gastroenterology 1985; 88 334-52

7 Whittle BJR, Steel G. Evaluation of the protection of rat gastric mucosa by a prostaglandin analogue using cellular enzyme marker and histologic techniques. Gastroenterology 1985; 88: 315-27.

8 Robert A, Lancaster C, Nezamis JE, Hanchar AJ. Cytoprotective prostaglandins, exogenous or endogenous, can maintain gastric secretory function [Abstract]. Gastroenterology 1978; 74: 1086.

9 Leung FW, Kauffman GL Jr, Washington J, Scremin OU Guth PH. Blood flow limitation of stimulated gastric acid Guth PH. Blood flow limitation of stimulated gastric

10 Schmidt KL, Bellard RL, Smith GS, Henagan JM, Miller TA Influence of prostaglandin on repair of rat stomach damaged by absolute ethanol. F Surg Res 1986; 41: 367-77.

11 Robert A, Schultz JR, Nezamis JE, Lancaster C. Gastric antisecretory and antiulcer properties of $\mathrm{PGE}_{2}, 15$-methyl $\mathrm{PGE}_{2}$, and 16,16-dimethyl $\mathrm{PGE}_{2}$. Intravenous, oral and intrajejunal administration. Gastroenterology 1976; 70 359-70. 